\title{
Threshold Mismatches between Pure-Tone Audiometry and Auditory Steady State Response in Non-Auditory Neuropathy Adults
}

\author{
Heil Noh and Hyesook Lee ${ }^{(1 D}$ \\ Department of Otorhinolaryngology-Head and Neck Surgery, St. Vincent Hospital, The Catholic University of Korea, Seoul, Korea
}

\author{
청신경병증이 아닌 성인의 순음청력검사와 청성지속반응검사의 역치값 불일치 \\ 노혜일 · 이혜숙 \\ 가톨릭대학교 성빈센트병원 이비인후-두경부외과학교실
}

\author{
Received October 23, 2019 \\ Revised December 18, 2019 \\ Accepted December 19, 2019 \\ Address for correspondence \\ Hyesook Lee, MD \\ Department of Otorhinolaryngology- \\ Head and Neck Surgery, \\ St. Vincent Hospital, \\ The Catholic University of Korea, \\ 93 Jungbu-daero, Paldal-gu, \\ Suwon 16247, Korea \\ Tel +82-31-249-7450 \\ E-mail hyesook1229@gmail.com
}

Background and Objectives To evaluate mismatches between pure-tone audiometry (PTA) and auditory steady-state response (ASSR) tests in non-auditory neuropathy adults and investigate brain lesions that may explain the mismatches, especially in cases where the ASSR threshold was worse than the estimated PTA threshold.

Subjects and Method PTA, speech audiometry, auditory brainstem response, ASSR, and neuroimaging tests were carried out on individuals selected. Among them, medical records of 30 subjects ( 16 males, 14 females; mean age $=54.4 \pm 13.2$ years) with significant mismatches between PTA and estimated ASSR thresholds were analyzed retrospectively. All neuroimaging tests were reviewed to identify any neurologic abnormalities.

Results Pathologic brain lesions were found in 19 cases (63.3\%) in the study group, all of which showed significant mismatch in hearing threshold between PTA and ASSR. Seven case of ischemic brain lesions (23.3\%), five tumorous lesions (16.6\%), and four brain vessel anomalies (13.3\%) were found. Brain hemorrhage due to trauma were found in two cases $(6.6 \%)$ as well as one case (3.3\%) of unruptured aneurysm. Central auditory pathway disorder was suspected in two cases. The 11 cases showing normal results in the imaging studies included one mental retardation, one brain concussion, and seven cases $(23.3 \%)$ with no specific causes. Six tinnitus cases included two subjects showing discrepancies between frequency matching in the tinnitogram.

Conclusion In adults with a mismatch between PTA thresholds and estimated ASSR thresholds, especially for those with moderate to profound hearing loss, additional neuroimaging tests and other audiologic tests may reveal other possible causes of hearing loss.

Korean J Otorhinolaryngol-Head Neck Surg 2020;63(8):350-7

Key Words Audiometry, evoked response · Audiometry, pure-tone · Auditory threshold · Hearing tests · Neuroimaging.

\section{서 론}

난청의 정도를 평가하는 청력검사에는 환자의 협조가 중요

This is an Open Access article distributed under the terms of the Creative Commons Attribution Non-Commercial License (https://creativecommons.org/licenses/by-nc/4.0) which permits unrestricted non-commercial use, distribution, and reproduction in any medium, provided the original work is properly cited.
한 주관적 검사법과 수동적인 피검자에서도 평가할 수 있는 객관적 검사법이 있다. 이 중 주관적 검사인 순음청력검사가 보편적으로 이용되는 검사법이나, 소아나 협조가 되지 않는 성인의 경우 신뢰할 만한 결과값을 얻기가 어려울 수 있다. 따라서 순음청력검사로 난청의 정도를 평가할 때 신뢰도를 높이기 위한 객관적인 검사법으로서 전기생리학적검사가 있 
으며 대표적으로 청성뇌간반응검사와 이보다 더 최근에 개발 된 청성지속반응검사가 있다. ${ }^{1,2}$

청성지속반응검사는 지속적인 변조음 자극에 의해 청각전 달로에서 발생하는 전기적 신호를 측정하며 자극음으로는 진 폭변조음, 주파수변조음, 그리고 진폭변조와 주파수변조를 혼합한 복합변조음 등의 자극음을 사용한다. 청성지속반응 검사는 1980 년대 개발되기 시작하여 국내에는 2000년초부터 여러 기관에서 사용되기 시작하였으며 현재까지 청성뇌간반 응검사와 함께 많이 사용되는 객관적 청력검사 중 하나이다. ${ }^{3)}$

청성지속반응검사의 역치값은 순음청력검사 역치값과 상 관관계가 매우 높은 것으로 보고된 바 있는데, Dimitrijevic 등 과 Cone-Wesson 등 ${ }^{5}$ 은 청성지속반응검사가 성인에서는 순음청력검사, 유소아에서는 행동반응관찰검사와의 상관관 계가 높음을 보고하였다. 국내에서도 소아 및 성인에서의 순 음청력검사와 청성지속반응검사의 상관관계를 분석한 선행 연구 결과가 있으며 소아와 성인 모두에서 높은 상관관계가 있는 것으로 보고되었다. ${ }^{6}$ 따라서 청성뇌간반응검사나 청성 지속반응검사 등의 객관적인 검사를 시행하여 순음청력검사 역치값의 신뢰도 확인이 가능하며 과장된 청력 손실이나 위 난청을 선별할 수 있다.

한편, 임상에서 순음청력검사를 통해 얻은 결과값이 청성 지속반응검사 등의 객관적 검사의 결과값과 크게 차이를 보 이는 경우가 있으며, 이는 전자가 후자보다 낮게 나오는 경우 혹은 후자가 전자보다 낮게 나오는 경우로 구분할 수 있다.

이에 저자들은 순음청력검사의 결과값이 청성지속반응검 사의 결과값과 불일치를 보이는 증례들 중에서 순음청력검사 역치값이 청성지속반응검사 결과보다 나쁘게 나온 경우를 분석하여 보고한 바 있으며, 처음에는 위난청을 의심하여 추 가로 위난청검사를 진행하였고, 뇌 MRI 등 영상검사에 의해 뇌병변 등에 의해서도 위와 같은 결과가 나올 수 있다는 점 을 보고하였다. ${ }^{7)}$

반대로 순음청력검사보다 청성지속반응검사의 결과값이 나쁘게 나오는 경우가 있으며, 기존의 연구에서는 청신경병 증이 있을 때 이와 같은 검사 결과가 나타날 수 있고 성인의 청신경병증에서 청성지속반응이 나타나지 않거나 나타나더 라도 그 값이 높게 나타난다고 보고하였다.89)

본 연구에서는 청신경병증 외에 청성지속반응의 결과값이 순음청력검사의 결과값보다 나쁘게 나올 수 있는 경우에 대 해 분석하였다. 이를 통하여 청신경병증 외에 다른 중추청각 계의 이상을 발견하고 난청의 정도를 평가하는 데 있어 객관 적 검사법인 청성지속반응검사의 임상적 유용성과 한계점을 고찰해보고자 한다.

\section{대상 및 방법}

\section{대 상}

2009년 11월 7일 2019년 8월 31일까지 청력 저하를 주소로 본원 외래를 내원하거나 혹은 타과에서 협진되어 시행한 순 음청력검사상 $0.5,1,2,4 \mathrm{kHz}$ 의 4분법 평균 역치에서 감각 신경성 난청으로 진단된 환자로서, 추가로 진행한 청성지속 반응검사의 결과값과 불일치를 보이는 환자를 선별하였다. 이후 순음청력검사의 결과값보다 청성지속반응검사의 결과 값이 나쁘게 나오는 경우 중 뇌 영상검사를 시행한 환자들을 연구 대상으로 포함시켰다.

환자의 기초 임상정보 및 검사 결과를 본원 전자의무기록 을 통하여 후향적으로 분석하였으며, 연구의 진행은 본원 윤 리위원회의 심의(과제번호: VC19RISI0196)를 받은 후 이루 어졌다.

\section{방 법}

\section{대조군 선정}

일측 돌발성난청 환자를 대상으로 순음청력검사의 결과값 과 청성지속반응의 결과값이 높은 상관관계가 있음을 입증한 이전 연구 결과를 토대로 ${ }^{10)} 2$ 차적 보상과 관련이 없는 일측 돌발성난청 환자에서 순음청력검사와 청성지속반응검사의 결과값 차이를 비교 분석하여 대조군 데이터로 사용하였다.

모든 환자에서 측두골 MRI를 시행하여 청신경 종양 등의 병변이 없음을 확인 후 대조군에 포함시켰다.

앞서 언급한 기간 동안 본원 이비인후과 외래에 내원하거 나 타과에서 협진되어 일측 돌발성난청으로 진단된 환자의 순음청력검사 역치값과 청성지속반응검사 역치값의 데이터 를 이용하여 두 검사 결과의 차이값을 분석하고 이를 토대로 불일치 기준을 설정하였다.

\section{대상 선정}

동일한 기간 동안 본원 이비인후과 외래에 내원하거나 타 과에서 협진된 난청 환자들을 대상으로 주관적 검사인 순음 청력검사와 어음청력검사를 시행하여 환자의 협조도가 양호 하고 검사 결과의 신뢰도가 높은 환자군을 선별하였다. 해당 환자군에서 청성지속반응검사를 시행하여 상기 불일치 기준 을 만족하면서 순음청력검사의 역치값보다 청성지속반응검 사의 결과값이 나쁘게 나오는 경우에 이들을 대상으로 다음 의 검사를 추가하였다.

1) 청신경병증을 감별하기 위해 이음향반사검사를 시행하 였다. 
2) 두부 손상의 과거력이 있거나 다른 신경학적 징후가 있 는 경우 기존에 본원에서 시행한 뇌 영상검사 자료가 있는 경 우 이를 확인하고 필요 시 추가 영상검사(MRI, magnetic resonance angiography, single photon emission computed tomography)를 시행하였다.

3) 영상학적으로 뇌병변의 증거가 없으면서 이명이 있는 경 우 이명도 검사를 시행하였다.

4) 환자에 따라 필요 시 인지장애에 대한 신경과적 검사를 시행하였다.

\section{청력검사 방법}

1) 순음청력검사는 TDH 49 supra-aural headphone을 이 용하여 정기적으로 교정받는 GSI $61^{\mathrm{TM}}$ (Grason-Stadler Inc., Eden Prairie, MN, USA) 청력계를 이용하여 검사하였으며 출력 간격은 $10 \mathrm{~dB}$ 씩 상승, $5 \mathrm{~dB}$ 씩 하강하는 수정 상승법으 로 측정하였고, 출력 범위는 $-5 \sim 110 \mathrm{~dB}$ 까지 측정하였다.

2) 어음청력검사는 최대 안정 수준(most comfortable level)에서의 어음분별력(discrimination score, \%)을 구하였다.

3) 병력상 소음에서의 말소리분별력 저하가 있는 경우, 음 장검사실에서 최대 안정 수준에서 신호 잡음 비율(signal noise ratio) $0 \mathrm{~dB}$ 의 음성 잡음(speech noise)을 동시에 주어 어음명료도(speech discrimination score, \%) 저하 정도를 확인하였다.

4) 이명이 있는 환자는 이명도 검사를 통해 이명의 성향(character), 주파수 일치도(pitch matching), 크기 일치도(loudness matching), 최소 차폐 크기(minimal masking level), 잔여 억 제(residual inhibition)를 측정하였다.

5) 청성뇌간반응검사는 Navigator pro EP(Bio-logic System, Mundelein, IL, USA)를 사용하였고 자극음은 클릭음 을 사용하였다. 출력 간격은 $10 \mathrm{~dB}$ 씩 조절하였고, 출력 범위 는 30 90 dB까지 시행하였다. 활성전극(active electrode)은 두정부에 위치하였고 기준전극(reference electrode)은 양측 유양 돌기, 접지전극(ground electrode)은 앞이마에 부착하 여 2-channel 전극을 사용하였다. 두 검사의 저항값은 모두 $5 \mathrm{k} \Omega$ 이하로 조정하였다.

6) 청성지속반응검사는 GSI Audera system(Grason-Stadler Inc.)의 각성검사(awake protocol)을 사용하였다. 자극음은
$0.5,1,2,4 \mathrm{kHz}$ 의 네 가지 이동주파수(carrier frequency)를 $100 \%$ 진폭변조(amplitude modulation), $10 \%$ 주파수변조 (frequency modulation)하였고 변조주파수(modulation frequency)는 $46 \mathrm{~Hz}$ 로 하였다.

음자극에 의해 유발된 파의 성분 중 자극음의 변조주파수 와 동일한 주파수를 가진 성분의 phase를 분석하여, 16 64회 자극 사이에 phase coherence의 $p$ value가 0.03 이하가 되 면 반응이 있는 것(phase locked)으로, 64회까지 $p$ value가 0.03 에 이르지 못하면 반응이 없는 것(random)으로 간주하 였다. 자극음을 $10 \mathrm{~dB}$ 간격으로 상승시키다가 반응이 있으 면 다시 $5 \mathrm{~dB}$ 간격으로 낮추어 역치를 구하였다.

\section{결과 분석}

연구 대상의 모든 검사 결과는 전자의무기록을 통하여 후 향적으로 분석하였으며, 다음과 같은 변수들을 이용하였다.

처음 진단 당시 나이, 성별, 좌우측, 이명의 유무, 뇌 영상검 사의 결과, 청성뇌간반응검사의 $\mathrm{V}$ 파에 의한 역치값, 순음청 력검사와 청성지속반응검사의 각 주파수에 따른 결과값( 0.5 , $1,2,4 \mathrm{kHz}$ )과 4분법 평균 역치값, 어음청력검사의 최대 안 정 수준에서의 어음명료도(\%), 일부 환자에서는 소음속말소 리검사(단음절을 이용한 신호 잡음 비율 $0 \mathrm{~dB}$ 의 차이값)를 포함시켰다. 특정 주파수 영역대만 역치값이 불일치하는 경 우, 이명이 있으면 이명주파수 영역과 불일치 주파수 영역대 와의 연관성을 분석하였다.

\section{결 과}

\section{대조군의 순음청력검사와 청성지속반응검사의 결과값 차이}

연구 기간 동안 일측 돌발성 난청으로 진단된 환자 56 명(남 27 명, 여 29명, 평균 나이 $53.0 \pm 13.6$ 세)의 병 측과 건 측의 두 청력검사 결과값 차이를 분석하여 대조군으로 사용하였 다(Table 1). 이전 뇌병변 병력이 없는 일측 돌발성난청 환자 군 중 측두골 MRI를 시행하여 청신경종양 등의 기질적 질 환이 없는 대상만을 대조군에 포함시켰다.

건 측의 순음청력검사와 청성지속반응검사의 각 주파수별 결과값 차이의 평균은 $0.5 \mathrm{kHz}$ 에서 $13.4 \pm 10.4 \mathrm{~dB} \mathrm{HL}, 1 \mathrm{kHz}$

Table 1. Difference between PTA thresholds and estimated threshold of auditory steady-state response at $0.5,1,2$, and $4 \mathrm{kHz}$ in the control groups. The worse ear and the better ear (4-frequency PTA average $<30 \mathrm{~dB}$ ) were analyzed separately

\begin{tabular}{lccccc}
\hline & $0.5 \mathrm{kHz}$ & $1 \mathrm{kHz}$ & $2 \mathrm{kHz}$ & $4 \mathrm{kHz}$ & 4-Frequency average \\
\hline Better ear $(\mathrm{dB} \mathrm{HL})$ & $13.4 \pm 10.4$ & $13.4 \pm 10.9$ & $17.8 \pm 11.5$ & $16.9 \pm 14.7$ & $12.1 \pm 8.3$ \\
Worse ear $(\mathrm{dB} \mathrm{HL})$ & $9.9 \pm 8.1$ & $9.9 \pm 9.1$ & $13.7 \pm 11.3$ & $13.0 \pm 11.4$ & $8.1 \pm 6.7$
\end{tabular}

Data are presented as mean \pm standard deviation. The 4-frequency average was calculated as the average of hearing threshold levels at $0.5,1,2$, and $4 \mathrm{kHz}$. PTA: pure-tone audiometry 
에서 $13.4 \pm 10.9 \mathrm{~dB}$ HL, $2 \mathrm{kHz}$ 에서 $17.8 \pm 11.5 \mathrm{~dB} \mathrm{HL}, 4 \mathrm{kHz}$ 에서 $16.9 \pm 14.7 \mathrm{~dB} \mathrm{HL}$ 이었으며 4 분법 평균 역치값의 차이 평균은 $12.1 \pm 8.3 \mathrm{~dB}$ HL이었다.

환 측의 순음청력검사와 청성지속반응검사의 각 주파수별 결과값 차이의 평균은 $0.5 \mathrm{kHz}$ 에서 $9.9 \pm 8.1 \mathrm{~dB} \mathrm{HL}, 1 \mathrm{kHz}$ 에서 9.9 $\pm 9.1 \mathrm{~dB} \mathrm{HL}, 2 \mathrm{kHz}$ 에서 $13.7 \pm 11.3 \mathrm{~dB} \mathrm{HL}, 4 \mathrm{kHz}$ 에서 $13.0 \pm 11.4 \mathrm{~dB}$ HL이었으며 4 분법 평균 역치값의 차이 평균은 $8.1 \pm 6.7 \mathrm{~dB}$ HL이었다.

순음청력검사와 청성지속반응검사의 각 주파수별 및 4분 법 평균 역치값의 차이 평균값이 환 측과 건 측 모두 $20 \mathrm{~dB}$ 이내의 차이를 보였으며 연구 대상자 수의 차이로 기인하여 평균값 표준편차의 차이는 있었으나 그 값이 국내의 선행 연 구와 비슷한 결과를 보였다. ${ }^{3)}$

한편, 순음청력검사와 청성지속반응검사의 결과값 차이를 비교한 여러 논문들을 분석하여 정리한 청각학 교과서에는, 각 연구 기관과 장비에 따라서 두 검사의 주파수별 결과값 차이의 평균값과 표준편차값이 다양한 범위로 나타날 수 있 음을 언급하고 있다. ${ }^{11)}$ 따라서 이를 참조하여 본 연구의 대조 군에서 얻은 결과를 토대로, 순음청력검사와 청성지속반응 검사의 불일치 기준을 각 주파수별 결과값의 차이가 $0.5 \mathrm{kHz}$ 와 $1.0 \mathrm{kHz}$ 에서는 각각 $20 \mathrm{~dB}$ 이상, $2.0 \mathrm{kHz}$ 와 $4.0 \mathrm{kHz}$ 에 서는 각각 $25 \mathrm{~dB}$ 이상, 4 분법 평균 역치값은 $15 \mathrm{~dB}$ 이상 차 이가 날 경우 불일치하는 것으로 본 연구 대상의 선정 기준 을 정하였다.

\section{연구 대상의 순음청력검사와 청성지속반응검사의 결과값 불일치 요인 분석}

2009년 11월 7일 2019년 8월 31일까지 순음청력검사와 청 성지속반응검사를 시행한 767 명의 난청 환자들 중 두 결과 값이 불일치를 보이는 경우는 30예로 $3.91 \%$ 의 비율을 보였 다. 연구 대상자 30 명(남 16 명, 여 14명, 나이 $54.4 \pm 13.2$ 세)의 기본 특성과 청력검사 결과를 Table 2에 정리하였다.

총 30명 중 19명(63.3\%)이 영상검사에서 의미 있는 소견을 보였으며, 이는 뇌졸중(stroke) 7명, 종양(tumor) 5명, 뇌혈관 기형 4명, 외상(trauma)에 의한 의한 뇌출혈 2명, 동맥류(aneurysm) 1 명 순이었다(Table 3).

일측 난청이 있는 25 명 중 16 명(64.0\%)이 영상검사에서 의 미 있는 소견을 보였으며, 이 중 난청이 있는 방향과 영상검 사에서 발견된 병변이 동 측인 경우가 8명, 반대 측인 경우가 7 명, 양측인 경우 1 명이였다. 양측 난청이 있는 5 명 중 3 명이 영상검사에서 의미 있는 소견을 보였으며, 이 중 2 명이 영상 검사에서 일측 병변이 확인되었고 1 명은 후방 교뇌 정중부 (posterior pons midline)에서 병변이 발견되었다.
영상검사에서 특이 소견이 없는 11명 중 7명은 원인 미상, 중추청각계 이상이 2명, 정신지체(mental retardation) 1 명, 뇌진탕 1 명이었으며 이 중 중추청각계 이상으로 진단된 환자 군(증례 20, 21번)은 소음속말소리검사(단음절을 이용한 신 호 잡음 비율 $0 \mathrm{~dB}$ 의 차이값)에서 현저한 저하를 보였다.

영상검사에서 특별한 원인을 찾을 수 없었던 7명 중 6명은 이명이 있었으며, 이명이 있는 환자 중 4 명은 불일치의 주파 수 영역이 이명 주파수 영역대(저음역, 고음역)와 중복되었으 며 나머지 2명은 무관하였다.

\section{고 찰}

다수의 선행 연구들이 순음청력검사와 청성지속반응검사 의 연관성을 보고하여 왔으며 임상에서 순음청력검사를 시 행하지 못하는 경우, 혹은 검사 결과를 보완하기 위하여 청성 지속반응검사를 이용하고 있다. 청성지속반응검사는 청성뇌 간반응검사보다 주파수 특이성이 높으며 자극하는 변조음의 최대 강도가 $120 \mathrm{~dB} \mathrm{HL}$ 이상으로 심도 난청 환자의 청력 역 치 측정이 용이하여 청각장애의 평가에 유용하게 적용될 수 있다. ${ }^{12}$ 그러나 순음청력검사와 청성지속반응검사의 결과값 이 불일치하는 경우를 임상에서 종종 볼 수 있는데, 이러한 결과 해석에 대해서는 아직 연구 결과가 많지 않아 확립된 바 가 없다. 순음청력검사의 결과값이 청성지속반응검사의 결과 값보다 더 나쁘게 나오는 경우, 가장 먼저 위난청의 가능성을 염두에 두고 검사의 신뢰도를 의심해 볼 수 있겠으나 이전 연 구에서 뇌병변이 있는 경우에도 이와 같은 결과를 나타낼 수 있음을 보고한 바 있다.7) 연구 대상자 25명 중 20명에서 뇌영 상 검사에서 이상 소견이 있었으며, 이 중 16 명(80\%)이 외상 환자였고 광범위한 영역의 뇌 손상이 확인되었다. 본 연구와 비교하였을 때 종양이나 뇌졸중의 비율은 낮았다. 한편, 또 다른 연구에서는 중추청각계에 병변이 있는 경우 순음청력검 사보다 청성지속반응검사의 결과값이 더 나쁘게 나올 수 있 음을 보고하였다. ${ }^{13)}$ 이 연구에서 중추청각계 병변이 있는 환 자를 대상으로 순음청력검사와 청성지속반응검사 결과값을 분석하였을 때 청성지속반응검사의 결과값이 $2 \mathrm{kHz}$ 에서 평 균 $24 \mathrm{~dB}$ 더 높게 나타났으며 이 결과를 통해 저자들은 청성 지속반응검사가 중추청각계 이상을 감별하는 데 도움이 될 수 있다고 하였다.

본 연구에서도 순음청력검사보다 청성지속반응검사의 결과 값이 나쁘게 나온 환자군의 뇌 영상검사를 분석하여 뇌병변 이 있는 경우를 다수 발견하였다. 연구 대상자 30명 중 19명 (63.3\%)에서 영상검사 결과 실제로 뇌병변이 확인되었으며, 나머지 11명에서는 영상검사에서 특이 소견이 발견되지 않았 


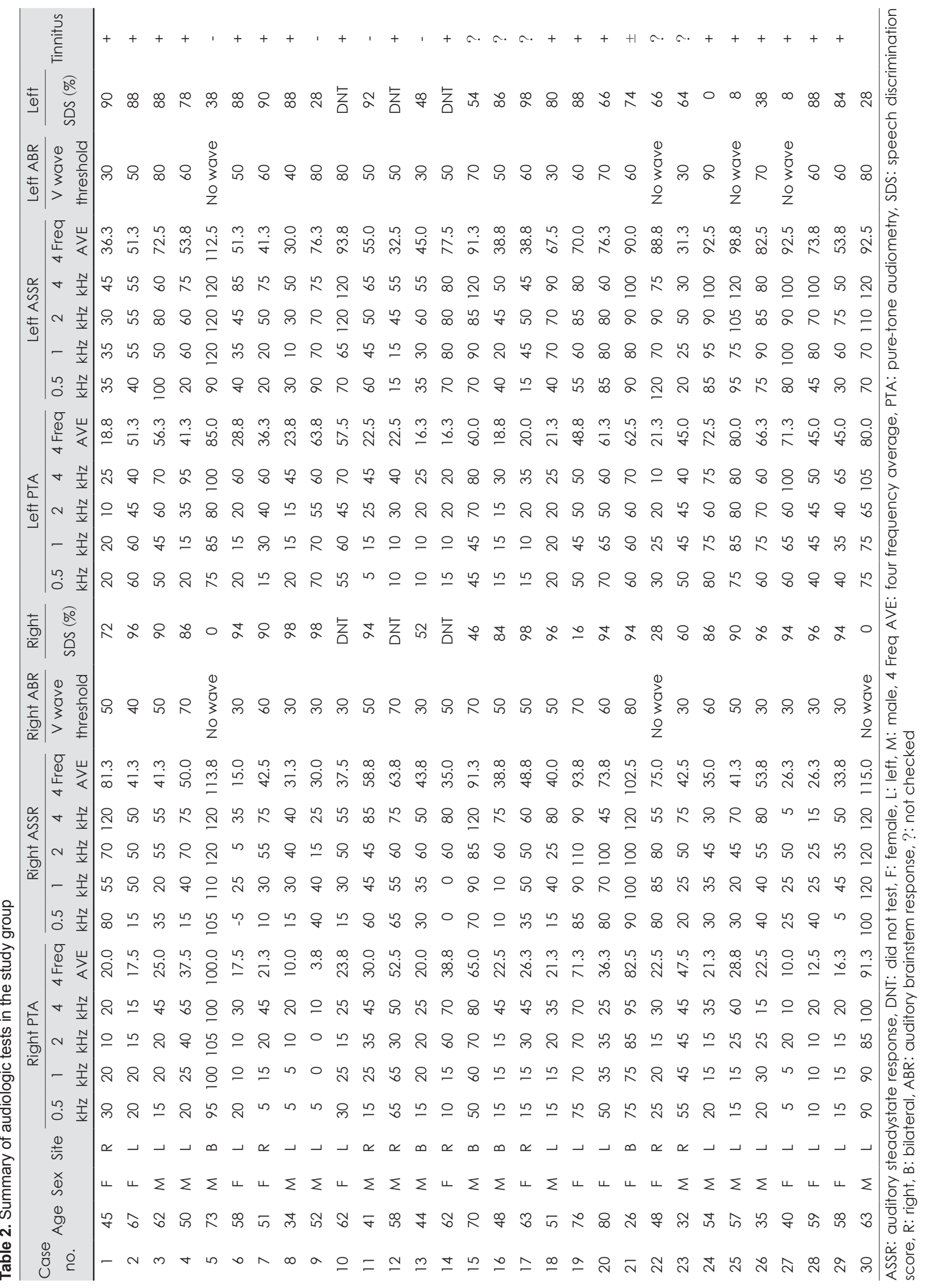




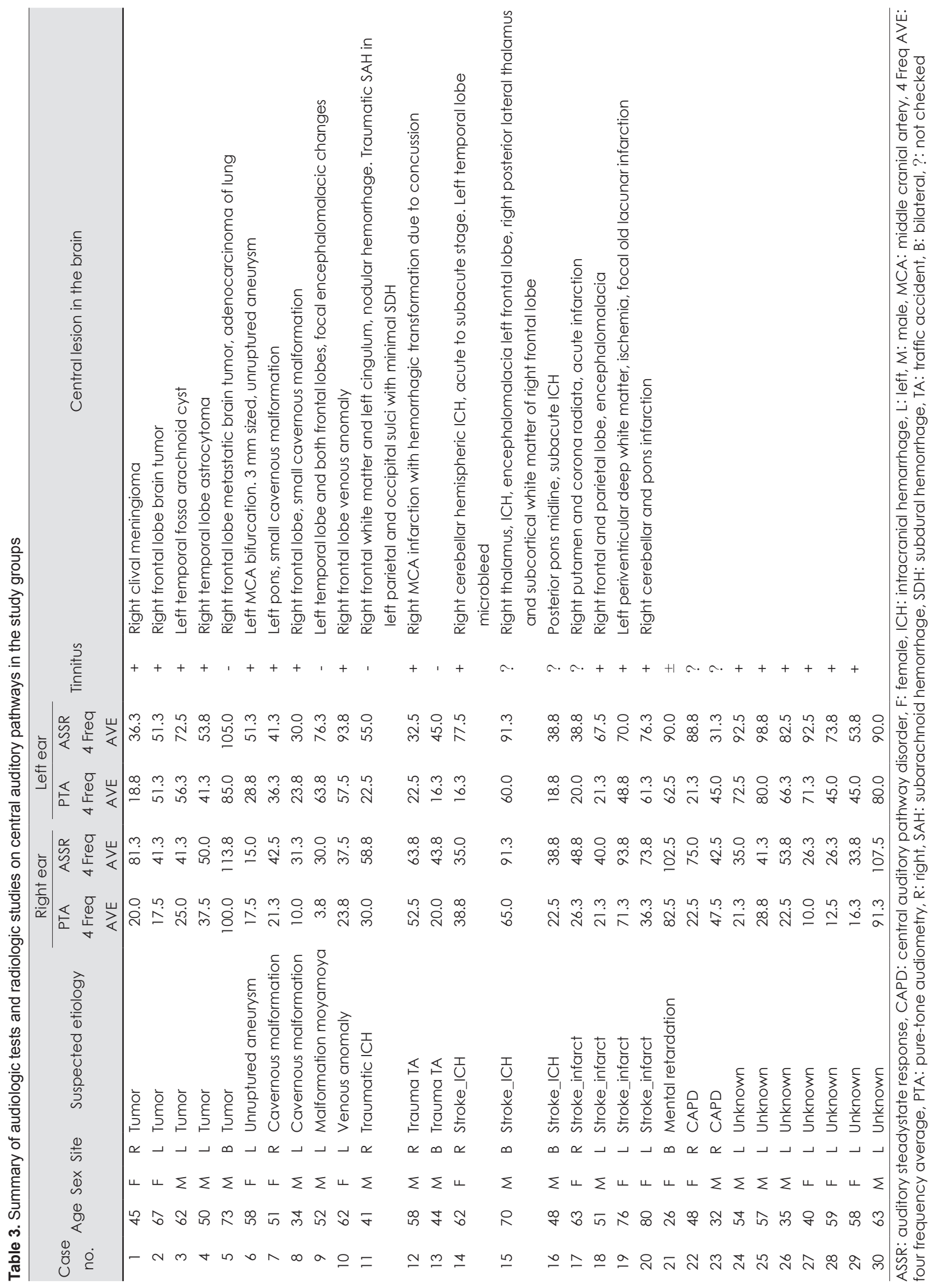


다. 영상검사에서 특이 소견이 없었던 환자들 중 경도의 외상 으로 인해 뇌진탕이 있었던 환자가 있었으며, 이전 연구에서 도 영상검사상 뚜렷한 뇌병변이 없는 외상 환자에서 청각 증 상이 나타나는 경우는 종종 보고된 적이 있다. 일례로 뇌진 탕이 있던 환자에서 경도 난청과 대뇌피질하부(subcortical level)의 중주청신경학적 변화, 그리고 이로 인한 소음 환경하 에서 청성뇌간반응검사의 $\mathrm{V}$ 파 최고조(peak)값과 잠복기의 이상이 보고되었다. ${ }^{14)}$

청신경병증은 아니면서 중추청각계 이상으로 난청이 나타 나는 경우 중추청각계 질환(central auditory pathway disorder)의 범주에 포함시킬 수 있고 이는 소음 환경에서 말소 리 분별력 저하가 심하게 나타나는 것으로 추측할 수 있다. 본 연구에서는 외상의 과거력이 없는 환자에서 병력상 소음 에서의 말소리분별력 저하가 있는 경우 소음속말소리검사를 시행하였으며, 2 명의 환자에서 말소리분별력 저하가 확인되 었다.

한편, Roche 등 ${ }^{15}$ 이 소아의 청신경병증 스펙트럼질환군 $\left(\mathrm{au}^{-}\right.$ ditory neuropathy spectrum disorder)을 대상으로 시행한 연구에서는 환자들의 $55 \%$ 에서 뇌 CT의 이상 소견이, $64 \%$ 에 서 뇌 MRI의 이상 소견이 발견되었다. 또 다른 연구에서는 청신경병증 환자에서 청성지속반응검사의 활용에 대한 한계 를 지적하였는데, 청신경병증 환자에서 청성뇌간반응은 나타 나지 않거나 매우 비정상적인 파형을 보이는 데 비해, 청성지 속반응은 정상적으로 나타날 수 있다고 보고하였다. ${ }^{16)}$ 또한 소아 청신경병증 환자에서 청성지속반응검사의 역치값이 순 음청력검사의 역치값과 일치하지 않는 것으로 널리 알려져 있 으며, 성인에서도 동일한 연구 결과가 있다. ${ }^{8,17)}$ 따라서 청성지 속반응검사만으로는 청신경병증을 진단할 수 없고, 실제 청 력 역치와 상관관계가 매우 약해 역치 측정의 의의도 떨어진 다. ${ }^{18)}$ 즉, 청성지속반응의 역치값 자체보다는 다른 검사와의 불일치성에 더 주목할 필요가 있으며 뇌 영상검사 등의 추가 검사가 도움이 될 수 있다.

그 외 원인 미상으로 분류된 환자 7명 중 6 명에서 이명이 있었다. 이 환자들에서 이명 자체의 주파수 영역대와, 그리고 순음청력검사와 청성지속반응검사의 역치값이 불일치하는 주파수가 중복되는 증례들이 있었고, 이러한 경우는 해당 주 파수 영역에서 위상결속(phase lock)의 변화가 왔다고 해석 해 볼 수 있다. 그러나 이명 주파수 영역대와 불일치 주파수가 모든 환자에서 동일하지는 않았다. Wienbruch 등 ${ }^{19}$ 의 이명 환자의 청성지속반응검사를 통한 주파수 구조(frequency organization)의 분열혼란(disruption)에 대한 연구에서도 이 명 주파수와 청성지속반응검사의 연관성이 유의한 수준은 아니었다.
한편, 연구 대상자 30 명 중 일측 난청이 25 명, 양측 난청이 5 명이었으며 이 중 영상검사에서 의미 있는 소견을 보인 환 자는 각각 16 명, 3 명이였다. 일측 난청 환자 중 난청과 영상검 사에서 발견된 병변이 동 측인 경우가 8명, 반대 측인 경우가 7 명, 양측인 경우가 1 명이었으며 난청 측과 뇌병변 측과의 상 관관계를 증명하기에는 부족하였다. 중추청각계는 주로 말초 의 반대편의 영향이 우세한 것으로 알려져 있으나 동 측에도 영향을 받을 수 있고, ${ }^{20)}$ 아직 그 경로가 완전히 규명되지 않 은 부분도 있다. 따라서 이러한 중추청각계의 복잡성에 기인 하여 본 연구에서는 단지 중추청각계와 관련된 뇌병변과 난 청의 간접적인 인과관계만을 추정할 수 있었다.

본 연구에서 시행한 일반적인 뇌 영상검사 및 소음속말소 리검사, 이명검사를 포함한 청력검사들에서 정확한 원인을 찾을 수 없는 원인 미상의 증례가 있었으며, 이는 현재 시행 하고 있는 검사들의 한계를 보여준다. 그러므로 중등도 이상 의 난청 판정 시 주관적인 청력검사와 객관적인 검사 결과값 들의 불일치가 있는 경우, 기존의 청력검사 외에도 추가로 뇌 영상 검사를 시행하는 것이 원인 규명에 도움이 될 수 있으 며, 최근 국내 연구에서 난청 환자를 대상으로 MRI를 이용 한 확산텐서영상(diffusion tensor imaging)을 개발하여 발 표한 것은 ${ }^{21)}$ 고무적인 업적이라고 생각한다. 따라서 임상에서 순음청력검사 결과값이 중등도 이상의 난청을 보이면서 청성 지속반응검사의 결과값과 예상치 않게 불일치를 보이는 경 우, 중추청각계 원인을 감별하기 위해 뇌 영상검사를 시행하 여 기질적인 문제를 우선 확인해 보아야 한다고 생각한다. 기 질적 뇌병변이 발견되지 않는 환자들에서 소음속말소리검사 나 이명이 어떠한 연관관계를 가지는지에 대해서는 후속 연 구가 필요하며, 궁극적으로는 난청의 원인과 정도의 판정에 서 기존 청력검사 결과값만을 이용하지 않고, 근거 중심의 판 정을 위하여 예외적인 상황에서도 객관성을 확보하기 위한 추가적인 검사의 개발이 필요하다고 생각한다.

\section{Acknowledgments}

None.

\section{Author Contribution}

Conceptualization: Heil Noh. Data curation: Heil Noh. Formal analysis: Heil Noh. Writing — original draft: all authors. Writingreview \& editing: all authors.

\section{ORCID}

Hyesook Lee

https://orcid.org/0000-0002-5903-696X

\section{REFERENCES}

1) Stevens J, Boul A, Lear S, Parker G, Ashall-Kelly K, Gratton D. Predictive value of hearing assessment by the auditory brainstem 
response following universal newborn hearing screening. Int $\mathrm{J}$ Audiol 2013;52(7):500-6.

2) Attias J, Buller N, Rubel Y, Raveh E. Multiple auditory steady-state responses in children and adults with normal hearing, sensorineural hearing loss, or auditory neuropathy. Ann Otol Rhinol Laryngol 2006;115(4):268-76.

3) Lee SH. Auditory Steady State Evoked Responses (ASSR). Korean J Otorhinolaryngology-Head and Neck Surg 2003;46(8):621-6.

4) Dimitrijevic A, John MS, Van Roon P, Purcell DW, Adamonis J, Ostroff $\mathrm{J}$, et al. Estimating the audiogram using multiple auditory steady-state responses. J Am Acad Audiol 2002;13(4):205-24.

5) Cone-Wesson B, Dowell RC, Tomlin D, Rance G, Ming WJ. The auditory steady-state response: Comparisons with the auditory brainstem response. J Am Acad Audiol 2002;13(4):173-87.

6) Park HJ, Kim HC, Shin DJ, Jang CH. Comparison between pure tone audiometry and auditory steady-state responses in Korean children and adult. Korean J Otorhinolaryngology-Head and Neck Surg 2015;58(3):182-6.

7) Noh H, Lee DH. Discrepancies in hearing thresholds between pure-tone audiometry and auditory steady-state response in nonmalingerers. Ear and Hearing 2020;41(3):663-8.

8) Kaga K. Auditory nerve disease and auditory neuropathy spectrum disorders. Auris Nasus Larynx 2016;43(1):10-20.

9) Jafari Z, Malayeri S, Ashayeri H, Farahani MA. Adults with auditory neuropathy: Comparison of auditory steady-state response and puretone audiometry. J Am Acad Audiol 2009;20(10):621-8.

10) Choi YH, Cho HH, Eom TH, Cho YB. The diagnostic value of auditory steady state response in patients of idiopathic sudden sensorineural hearing loss. Korean J Otorhinolaryngology-Head and Neck Surg 2015;58(4)243-8.

11) Kartz J, Chasin M, English K, Hood LJ, Tillery KL. Handbook of clinical audiology. 7th ed. Philadelphia, PA: Wolters Kluwer;2015. p. $270-83$.
12) Lee HS, Ahn JH, Kim YJ, Lee KS, Yoon TH, Chung JW. The correlation between pure tone audiometry and auditory steady state response according to the hearing level and frequency. Korean $\mathrm{J}$ Otorhinolaryngology-Head and Neck Surg 2006;49(6):593-7.

13) Shinn JB, Musiek FE. The auditory steady state response in individuals with neurological insult of the central auditory nervous system. J Am Acad Audiol 2007;18(10):826-45.

14) Vander Werff KR, Rieger B. Brainstem evoked potential indices of subcortical auditory processing after mild traumatic brain injury. Ear Hear 2017;38(4):e200-14.

15) Roche JP, Huang BY, Castillo M, Bassim MK, Adunka OF, Buchman CA. Imaging characteristics of children with auditory neuropathy spectrum disorder. Otol Neurotol 2010;31(5):780-8.

16) Kim LS, Jeong SW. Hearing threshold prediction using auditory brainstem response and auditory steady-state response in infants and young children. Korean J Otorhinolaryngol-Head Neck Surg 2011;54(9):592-602.

17) Lalayants MR, Brazhkina NB, Geptner EN, Kruglov AV, Barrlyak VV, Tavartkiladze GA. [Auditory evoked potentials in children with auditory neuropathy spectrum disorder]. Vestn Otorinolaringol 2018;83(4):15-20.

18) Rance G, Beer DE, Cone-Wesson B, Shepherd RK, Dowell RC, King AM, et al. Clinical findings for a group of infants and young children with auditory neuropathy. Ear Hear 1999;20(3):238-52.

19) Wienbruch C, Paul I, Weisz N, Elbert T, Roberts LE. Frequency organization of the $40-\mathrm{Hz}$ auditory steady-state response in normal hearing and in tinnitus. Neuroimage 2006;33(1):180-94.

20) Pickles JO. An introduction to the physiology of hearing. 2nd ed. London: Academic Press;1988. p.180-1.

21) Jang $\mathrm{SH}$, Bae $\mathrm{CH}$, Seo JP. Injury of auditory radiation and sensorineural hearing loss from mild traumatic brain injury. Brain Inj 2019;33(2):249-52. 